\title{
A CASE OF DICOUMarol POISONING
}

BY

J. A. WAKES MILLER, M.B., M.R.C.P.

Physician, Hospital of St. Cross, Rugby, and Nuneaton General Hospital

AND

J. K. DRUCQUER, M.B., Ch.B.

Clinical Assistant, Medical Unit, Hospital of St. Cross, Rugby

The following case emphasizes the grave danger of the use of the anticoagulant dicoumarol without adequate laboratory control. It also stresses the importance of the use of fresh blood and not stored blood in the therapeutic control of haemorrhage from dicoumarol overdosage. Vitamin $\mathrm{K}$ and stored blood are without effect. There is a definite latent period before therapeutic measures can take effect, and various mechanical factors may have to be dealt with. The reaction to treatment, when it occurs, is dramatic, and no case can be considered hopeless. In this instance, despite the severe and generalized nature of the haemorrhages, complete recovery occurred.

\section{Case Report}

The patient, a man aged 57, was admitted to hospital on account of severe haematuria on Oct. 4, 1947. He had read in the daily papers that dicoumarol had been used for coronary thrombosis, but it was not known that the cause of the haematuria was dicoumarol until a detailed history was taken, and by this time various other severe haemorrhagic symptoms were present. It was revealed that on his own initiative he had taken $100 \mathrm{mg}$. daily for nine or ten days. There was a latent period of seven days before signs and symptoms appeared. This latent period has been previously pointed out by Crawford and Nassim (1944). The first symptom was abdominal pain, which preceded sudden gross haematuria by 24 hours.

Within 24 hours of being admitted to hospital the patient's general condition deteriorated rapidly. Multiple petechial haemorrhages occurred in the skin and subcutaneous tissues, then melaena and a massive sublingual haematoma developed which increased in size hourly. The initial B.P. was $160 / 115$. The tongue became the size of a tangerine orange and immediately threatened to obstruct his airway. Despite the immediate transfusion of blood the swelling of the tongue increased and a tracheotomy was performed while transfusions were continued. A considerable submandibular haematoma developed and the patient was in extremis. His B.P. was $90 / 74$ on Oct. 7 . The anoxaemia was relieved but haemorrhages continued. A pint $(570 \mathrm{ml}$.) of stored blood was given, with vitamin $\mathrm{K}$ injections intramuscularly ; the response was not satisfactory, and haemoptyses occurred. $X$-ray examination with a portable apparatus revealed multiple shadows in the lung fields. Further transfusion of 1 pint of fresh blood was given on Oct. 8, but his condition remained precarious. A further 3 pints (1.7 litres) of blood was obtained from the relatives, and this was given by slow drip over the next 48 hours. His condition gradually improved and the haematuria and petechial haemorrhages decreased. Whole-blood transfusion had a dramatic effect on the prothrombin times. These were: Oct. 7, 47\% normal; Oct. 8, 48\% normal ; Oct. 9, 50\% normal ; Oct. $17,57 \%$ normal.

Examination of the blood on Oct. 5 showed: haemoglobin, $82 \%$; red cells 3.600 .000 ; white cells, 12,200 ; reticulocytes, $3 \%$; platelets, 108.000 . On Oct. 10 the haemoglobin was $50 \%$. On the 14th the white cells numbered 8.000 , reticulocytes $7 \%$, platelets 240.000 . On the 17 th the haemoglobin was $97 \%$; red cells, 4.800,000; white cells, 8,600; reticulocytes, 5\%; platelets, 288,000 .

\section{Discussion}

Dicoumarol must be considered in the differential diagnosis of all cases of haematuria in which the drug has been taken. This is discussed by Rosenbloom and Crane (1946). It would appear that haematuria is one of the earliest signs of dicoumarol intoxication and an indication for correct therapy, as more severe symptoms may quickly supervene in a matter of hours. In our case venesection before transfusion was not performed, as was practised by Shlevin and Lederer (1944), although there was a definite danger of left-sided heart failure from a recent coronary thrombosis. Jaundice developed 130 days after the initial transfusion. This was taken to be of the homologous serum type rather than due to any direct toxic action of the dicoumarol on the liver. Jaundice as a manifestation of dicoumarol poisoning has not yet been reported. The present case, we think, illustrates the importance of including dicoumarol in the list of dangerous drugs.

Grateful thanks are due to Sister B. Coysh for correlation of clinical details, to Mr. F. J. C. Matthews, assistant surgeon, for performing the tracheotomy, to Dr. R. C. Hill, pathologist, and to Mr. F. J. Howe, Hospital of St. Cross.

\section{REFBRENCES}

Crawford, T., and Nassim, J. R. (1944). Lancet, 2, 404.

Rosenbloom, D., and Crane, J. J. (1946). J. Amer. med. Ass., 132, 924.

Shlevin, E. L. and Lederer, M. (1944) Ann. intern. Med., 21, 332.

\section{Medical Memoranda}

\section{Auricular Fibrillation after Trichlorethylene Anaesthesia}

The following case is unusual enough to merit publication. It is of interest in that although the occurrence of vagal inhibition (Haworth and Duff, 1943), sinus bradycardia, and auricular and ventricular extrasystoles (Hewer, 1942, 1943 ; Barnes and Ives, 1944) has been noted during anaesthesia with trichlorethylene, there is only one record in the current literature (Lloyd-Williams and Hewspear, 1942) describing the onset of auricular fibrillation in association with this form of anaesthesia, although by now innumerable administrations have been given in this country alone.

\section{CASE History}

A healthy woman aged 50 was admitted to hospital for the repair of a large cystocele and rectocele. She had always been in excellent health, and at the pre-operative examination she appeared to be very fit, with no clinical evidence of cardiovascular disease. The blood pressure was $140 / 90$. She was, however, unduly nervous and apprehensive.

Pre-operative medication consisted of $1 / 6 \mathrm{gr}$. $(11 \mathrm{mg}$.$) of$ morphine and $1 / 150 \mathrm{gr}$. $(0.43 \mathrm{mg}$.) of hyoscine. Anaesthesia was induced with $0.5 \mathrm{~g}$. of sodium thiopentone, and this was followed by nitrous oxide, oxygen, and trichlorethylene, using a "semiclosed" technique with the standard Boyle machine. Induction and maintenance were smooth and uneventful. Anoxia was not permitted at any time, and there were none of the usual signs to indicate overdosage of the drug-which was not surprising, as an absolute minimum was used. No irregularities of the pulse were noted during operation, which lasted 55 minutes. At the end of the operation the patient's general condition was good, but the pulse rate was rather slow (65).

Fifteen minutes later we were called to the ward; she was almost conscious, but sweating profusely and rather pale, with a pulse rate of 40 . In the absence of other findings it was considered that this might be a vagal effect and $1 / 100 \mathrm{gr}$. $(0.65 \mathrm{mg}$.) of atropine sulphate was given intravenously. Within two minutes the pulse rate had returned to $65-70$ and remained so, although from time to time multiple extrasystoles could be detected by palpation and auscultation. Four hours later we were again called to see her and found that she was dyspnoeic and slightly cyanosed, but apart from the dyspnoea she felt quite comfortable. On examination auricular fibrillation was present with a ventricular rate of approximately 165 . There were no other abnormal clinical signs. A course of intensive "digoxin " therapy was instituted. The following morning auricular fibrillation was stilf present, but the ventricular rate was down to 100 and the cyanosis and dyspnoea had disappeared. By evening the fibrillation had ceased and the cardiac rhythm was completely regular, the pulse rate being 75 . Digoxin was discontinued and the cardiac rhythm remained normal. Further convalescence was uneventful. Unfortunately it was impossible to have an electrocardiogram taken during the period of fibrillation, but clinically the diagnosis was never in 
doubt. Electrocardiograms taken subsequently showed no abnormality in rhythm or evidence of myocardial disease. There was no evidence of thyrotoxicosis and the blood Wassermann reaction was negative. One month after operation the patient was symptomless and was carrying out her normal household duties.

\section{COMMENT}

The work of Meek, Hathaway, and Orth (1937) and Meek (1940) has provided useful information with regard to the effects of anaesthetic agents on cardiac automaticity. It seems likely that arrhythmias arising below the sino-auricular node are due to vagal stimulation, which causes depression of the sinoauricular node, bradycardia, and the appearance of auricular and ventricular extrasystoles (escape phenomena). Because of this depression of the sino-auricular node the ventricular muscle is rendered more sensitive to stimulation, particularly by adrenaline, and ventricular fibrillation may occur. This is presumably the mechanism of ventricular fibrillation occasionally seen during chloroform anaesthesia. Trichlorethylene is of course very similar to chloroform in chemical composition, and clinical reports bear out this similarity of action, although it is much less toxic and potent. Waters, Orth, and Gillespie (1943), basing their opinion on only a few cases, decided that the drug might have undesirable effects on cardiac automaticity, but up to the present time clinical experience has not really justified this view. In their electrocardiographic investigation of $\mathbf{4 0}$ patients undergoing operations under trichlorethylene anaesthesia Barnes and Ives (1944) demonstrated various simple arrhythmias such as sinus bradycardia and auricular and ventricular extrasystoles, but found no evidence of auricular or ventricular fibrillation.

In our case the sequence of events - vagal stimulation with bradycardia, extrasystoles (presumably auricular), and auricular fibrillation-was well demonstrated. Theoretically there would seem to be no reason why auricular fibrillation and not ventricular fibrillation should not follow on multiple auricular extrasystoles in the absence of suitable ventricular stimulatione.g., excess adrenaline. This case is of further interest in that the cardiac arrhythmias occurred in the immediate post-operative period, when presumably most of the trichlorethylene had been excreted. Adrenaline was not used during operation nor was the patient intubated-factors present in the other recorded case. In view of the patient's state of health both before and after operation it is difficult to dissociate the trichlorethylene anaesthesia and the onset of fibrillation.

It should be noted that the trichlorethylene used in this case was from a newly opened bottle which when subsequently examined conformed to the usual tests of purity. Several patients have since been anaesthetized with trichlorethylene from the same bottle without untoward effect.

\section{Royal Infirmary, J. B. EwING, M.D., F.R.C.S.}

Wigan, Lancs.

G. J. C. BRItTAIN, M.D., D.A.

\section{REFERENCES}

Barnes, C. G., and Ives, J. (1944). Proc. R. Soc. Med., 37, 528.

Haworth, J., and Duff, A. (1943). British Medical Journal, 1, 381.

Hewer, C. L. (1942). Proc. R. Soc. Med., 35, 463.

(1943). Ibid., 36, 463.

Lloyd-Williams, K, and Hewspear, D. (1942). British Medical Journal, 2, 170

Meek, W. J. (1940). Proc. Mayo Clin., 15, 237.

Wathaway, H. R., and Orth, O. S. (1937). J. Pharmacol., 61, 240.

Waters, R. M., Orth, O. S., and Gillespie, N. A. (1943). Anesthesiology, 4, 1

\section{An Unusual Trophic Ulcer}

Numerous papers have been written on lesions of the lumbar intervertebral disks and their relation to sciatic pain since the pathology was described by Love in 1939. In addition to sciatic pain other conditions have been ascribed to disk lesions. Massive extrusions of the lumbar disks are known to produce cauda equina lesions with severe sphincter disturbances (ver Brugghen, 1945). Pennybacker (personal communication) has seen trophic ulcers complicating cauda equina lesions due to prolapse of the lumbar disks. Burns and Young (1945) attribute the majority of cases of chronic backache to disk lesions.

Search of the extensive literature has failed to reveal any reference to a.trophic ulcer of the foot being produced by an old lesion of a lumbar intervertebral disk, and it is thought that the following case is of sufficient interest and importance to merit publication.

The usual causes of trophic ulcers given in neurological textbooks are tabes dorsalis, diabetes, spina bifida occulta, leprosy, and syringomyelia (rarely). As trophic ulcers are not uncommon it is possible that not a few are due to old disk lesions which have been missed because the more usual causes are not common maladies, with the single exception of diabetes. Furthermore, Schmorl (1927) finds prolapse of an intervertebral disk present in $38 \%$ of necropsies. Leigh (1947) points out that sensory regeneration may not occur, as compression of the nerve root in disk lesions involves the sensory fibres most of all.

\section{Case Report}

A truck-driver aged 29 was referred from the surgical to the medical out-patient department on account of an absent right anklejerk. In March, 1947, he was seen in the surgical out-patient department on account of an excavated and discharging ulcer on the plantar surface of his right heel. It was painless and had been present for about 10 weeks. He denied injuring his heel. Excision was advised. A week later he was admitted to a surgical ward, and two days later the ulcer was excised under a general anaesthetic. The wound was packed with vaselined gauze. He was discharged after a week; a radiograph of the foot taken at this time showed that there was no bony lesion or radio-opaque foreign body in the heel. A week later the ulcer was healing satisfactorily. A section of the ulcer showed "capillary thromboses and haemorrhages in dermal papillae in a portion of horny skin from the heel."

He was seen again on Aug. 11, 1947, when he said that the ulcer had broken down some eight weeks previously, but it was still painless. Further inquiry into his history elicited the following information: In March, 1944, he had had pain in the right side of the back, buttock, and down the back of the thigh and leg to the lateral border of the foot and of the heel ; the pain had lasted 10 weeks and he had been away from work for six weeks. When the pain had subsided it had been replaced by numbness of the outer side of the right foot and heel. There was no history of trauma. At no time had there been any disturbance of micturition.

On examination he was seen to be a healthy-looking man. The only abnormal neurological signs in the legs were an absent right ankle-jerk and marked impairment of pain and touch sensibility over the lateral border of the foot, both dorsal and plantar surfaces of the heel, and of the posterior aspect of the thigh. Flexion of the extended leg at the hip was painless (Lesègue's sign negative). The ulcer measured 1 by $1 \mathrm{~cm}$. and was $0.5 \mathrm{~cm}$. deep; it had a granulated base and undermined edges. The arteries of the right foot were easily palpable. There was some loss of normal lumbar lordosis and flattening between the fifth lumbar spine and the first piece of the sacrum. There was no tenderness anywhere, and movements were full. No other abnormal physical signs were found in the central nervous system. Wassermann and Kahn reactions were negative. Radiographs showed no abnormality of the lumbo-sacral region.

It was not considered justifiable to submit this patient to laminectomy ; his disability was slight, he was at work, and the long history suggested damage to the posterior nerve root which was probably permanent. Accordingly local treatment to the ulcer was intensified.

This case well illustrates the following points : (1) The typical sciatic pain in 1944 was replaced by numbness over the lateral side of the foot and heel-a point which is often missed in the history, as the patient pays little attention to numbness compared with the severe pain; the numbness tends to persist. The length of the history and the absence of progression of symptoms almost certainly exclude a very slowly growing tumour compressing the first sacral nerve root. (2) The abnormal neurological physical signs and flattening of the lower lumbar spine suggest a prolapse of the disk between the fifth lumbar and first sacral vertebrae. These signs tend to persist. (3) The ulcer was no doubt due to the impairment of pain sensibility, which corresponds to the sensory division of the first sacral nerve root; it was this root which was compressed by the extruded disk. (4) The relation of the sciatic pain three years previously was not correlated with the ulcer of the foot until the question of the absent ankle-jerk presented itself for elucidation.

My thanks are due to Dr. S. A. Propert. honorary physician, and Mr. Ronald Reid, honorary surgeon, Essex County Hospital, Colchester, for their interest and encouragement in the preparation of this report.

\section{J. C. W. Hopkyns, B.M., M.R.C.P. Essex County Hospital, Colchester.}

\section{REFERENCES}

Burns, B. H., and Young, R. H. (1945). Lancet, 2, 424

Leigh, A. D. (1947). Postgrad. med. J., 23, 141.

Sove, J. G.91939). Proc. R. Soc. Med., 32, 1697.

ver Brugghen, A. (1945). Surg. Gynec. Obstet. 81, 269. 